\title{
Interactive Fitness Game for Public Places
}

\author{
Ekaterina Kurdyukova \\ University of Augsburg \\ Universitätsstr. 6a \\ 86159 Augsburg, Germany \\ Katja.Kurdyukova@informatik.uni-augsburg.de
}

\author{
Matthias Rehm \\ University of Augsburg \\ Universitätsstr. $6 a$ \\ 86159 Augsburg, Germany \\ Rehm@informatik.uni-augsburg.de
}

\begin{abstract}
We present a concept of a fitness game that can be installed in public places and encourage passers-by to participate in a short play. The game is controlled by players' body motions and thus provokes physical exercises. Moreover, the game encourages social interactions between players, if played in multi-user mode. To play the game a person needs a mobile phone with accelerometer. We describe the game design based on engagement theories and the first evaluation results. The game can beneficially combine physical exercises and social interactions in a playful way.
\end{abstract}

\section{Categories and Subject Descriptors}

H.5.2 [User Interfaces]: Interaction styles, input devices and strategies.

\section{General Terms}

Design, Human Factors.

\section{Keywords}

Physical activity, social interactions, engagement, fitness games.

\section{INTRODUCTION}

Minutes and hours spent while waiting for a bus, a friend, or in a waiting room can be efficiently used to add some physical activity to the day and to socialize with others. In this paper we present the design of a public fitness game that attracts passers-by to participate in a spontaneous play. The game is controlled by energetic body motions and can be played in pairs.

It is a challenging task to design an engaging game for public places. We provide the insights from engagement theories and show how we applied them to the design of our fitness game. In contrast to existing fitness games we try to include various engagement factors in the game at the same time. Moreover, we aim to find out which combination of these factors is preferred by the players and how it contributes to their game experiences.

Permission to make digital or hard copies of all or part of this work for personal or classroom use is granted without fee provided that copies are not made or distributed for profit or commercial advantage and that copies bear this notice and the full citation on the first page. To copy otherwise, or republish, to post on servers or to redistribute to lists, requires prior specific permission and/or a fee.

ACE'09, October 29-31, 2009, Athens, Greece.

Copyright 2004 ACM 1-58113-000-0/00/0004...\$5.00.

\section{ENGAGEMENT FACTORS IN GAMES}

This section summarizes the main findings on engagement in entertaining games, learning games, and simulation games that are useful for our fitness game concept.

\subsection{Game Factor}

Designing an application as a game is itself a well-known way to increase engagement [1]

Malone [2] describes three game aspects that affect engagement and pleasure of players: challenge, fantasy, and curiosity. Challenge in a game is supported by goal structures. Simple games should have obvious goals; complex games should provide clearly structured intermediate goals. Fantasies, the second aspect mentioned by Malone, evoke images that are not physically present. Finally, Malone emphasizes the curiosity aspect. He recommends designers to exploit sensory and cognitive curiosity to raise the players' engagement and add appeal to the game. In a public fitness game the "challenge" principle of Malone can be realized by a challenging interaction technique that requires physical effort. "Fantasy" and "curiosity" principles should be addressed by game scenario and unusual design solution.

\subsection{Narrative Factor}

One of engagement factors described by Caluwé et al. [3] is related to the narrative perspective of gaming. According to the authors, the attractive narrative maintains the suspense in the story, increases the interest in the game, and encourages players to dive into the game scenario. The power of the role play, the value of group support, emotional foundation of cognition and behavior can be seen as engagement facilitators. Mapping this theory to public fitness games, designers should provide a game scenario with an immersive narrative which is easy to understand and follow.

\subsection{Social Factor}

The presence of game partners in a play (virtual or real) is another well-known engagement booster [3]. Social factor can be supported by group play, competition, or the presence of spectators. A number of experiments show that importance of either of these social counterparts $[4,5,6]$.

The shape of social interaction plays important role in the game experience. For example, a group play is known to provoke collaborative discussions, competition often increases the game results. Vorderer et al. [1] study the competition factor on example of video games. The authors claim that "the user's feeling to play against an opponent likely evokes a social- 
competitive situation that should be especially capable to engage and to involve the user." We believe that competition in fitness games should also have a strong engagement effect.

\section{GAME DESIGN}

Following the heuristics from the engagement theories we designed a prototype for the public fitness game. The players stand in front of the projected game field that shows six areas. One randomly chosen area is highlighted at a time. The user gets a point if he quickly moves his icon into the highlighted field. The game can be played alone (against a virtual rival or in story mode) or in pairs (against a real rival). In the story-based mode user follows a spacemen story where he has to "catch" the stars in order to reach his destination (see Fig.1, right). The final version of the game is supposed to have only two modes: a single play and a pair play. However, we need to find out which variations of pair- and single plays are preferred by the users (virtual or real rival, with story or without).
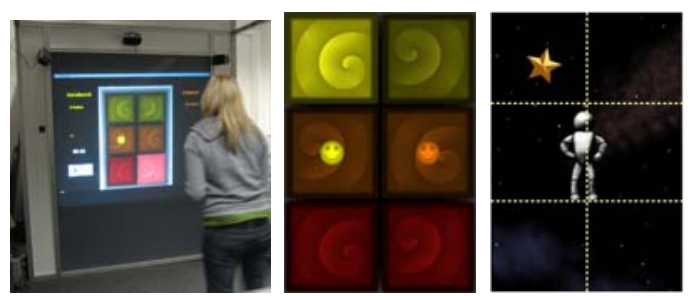

Figure 1. User playing in a single mode (left), screen of the competition mode (middle), story mode (right).

The game is controlled by means of active body actions. So far we have used an accelerometer to recognize user body motions. Due to the nature of accelerometer, the user has to move very energetically along one axis in order to create sufficient impulse on the desired axis. Therefore, the players are challenged to apply some physical effort.

Every game lasts about three minutes. This duration is long enough to get a small physical exercise and at the same time short enough to be played spontaneously in a public play.

\section{FIRST EVALUATION}

First evaluation revealed user preferences in training modes, and provided general feedback about the game.

Thirty users has participated in the trial experiment, 23 male and 7 female, all of them were students. Every test person hast to play three modes: competition against virtual rival (single play), competition against a real rival (pair play) and a story-based game (single play). The users made their preferences at the end.

The results clearly showed that the users prefer the competition against a real rival. The users liked the opportunity to observe their opponents, see their emotions, exchange comments. Moreover, observations helped them to adjust their playing strategy. The game was found more exciting, if the opponents were friends or familiar to each other.

The story mode was preferred by one fifth of test participants. We believe that such low rate is caused by the simplicity of the story: in the short game time it is hard to develop a real dramatic plot and immerse users into the story. However, if the users play alone, they would clearly prefer the story play to the virtual rival mode.

The early results prove that the social factor is a very strong engagement facilitator that is probably stronger than the narrative factor if taken separately. However, the story-based design appeared to be more attractive than a design with no story. Therefore, in the final version of the game we will include two modes: a story-based single play and a story-based competition for real opponents.

\section{CONCLUSION}

We described the concept of a fitness game that can be installed in public locations. The prototype of the game was based on engagement theories. It exploits the narrative engagement factors, social factors, and follows the guidelines of entertaining game design, expressed by Malone [2].

The evaluation of the prototype has shown that in a pair play the users prefer to play in competition with their friends or people they know. For a single play they prefer a story-based game. However, the story scenario should be improved to enhance user interest and immersion into the game.

The future version of the game will introduce story-based modes for single and pair plays. To increase immersion in the game, the story can be related to the surrounding environment. The story can also have an educative component: e.g. players can learn about city history from the story.

\section{ACKNOWLEDGEMENTS}

This work was supported by the EC and has been funded by the project IRIS (FP7-ICT-231824).

\section{REFERENCES}

[1] Vorderer, P., Hartmann, T., Klimmt, C.: Explaining the Enjoyment of Playing Video Games: The Role of Competition. In: 2nd International Conference on Entertainment Computing, pp. 1-9. Carnegie Melon University, Pittsburg (2003)

[2] Malone, T.W.: What Makes Things Fun to Learn? Heuristics for Designing Instructional Computer Games. In: 3rd ACM Symposium on Small Systems, pp. 162-169. ACM Press, New York (1980)

[3] Caluwé, L., Hofstede, G.J., Peters, V.: Why Do Games Work? Kluwer, Deventer (2008)

[4] Mueller F., Stevens G., Thorogood A., O’Brien S., Wulf V. Sport over Distance, Personal and Ubiquitous Computing, Volume 11, Issue 8, Dec. 2007, p. 633-645

[5] Blinkenlights http://www.blinkenlights.net/

[6] O’Hara, K., Glancy, M., Robertshaw, S.: Understanding collective play in an urban screen game. In: ACM Conference on Computer Supported Cooperative Work, pp. 67-76. ACM Press, New York (2008) 